\title{
8
}
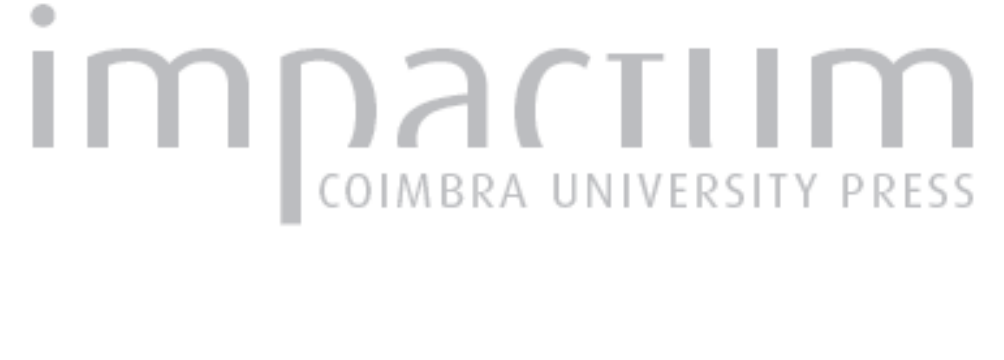

\section{Hannah Arendt e o "milagre" da natalidade}

Autor(es): Vicente, José João Neves Barbosa

Publicado por: $\begin{aligned} & \text { Universidade Católica de Petrópolis; Instituto Brasileiro de Informação } \\ & \text { em Ciência e Tecnologia }\end{aligned}$

URL

persistente:

URI:http://hdl.handle.net/10316.2/33049

DOI:

DOI:http://dx.doi.org/10.14195/1984-6754_3-1_3

Accessed : $\quad$ 26-Apr-2023 15:50:23

A navegação consulta e descarregamento dos títulos inseridos nas Bibliotecas Digitais UC Digitalis, UC Pombalina e UC Impactum, pressupõem a aceitação plena e sem reservas dos Termos e Condições de Uso destas Bibliotecas Digitais, disponíveis em https://digitalis.uc.pt/pt-pt/termos.

Conforme exposto nos referidos Termos e Condições de Uso, o descarregamento de títulos de acesso restrito requer uma licença válida de autorização devendo o utilizador aceder ao(s) documento(s) a partir de um endereço de IP da instituição detentora da supramencionada licença.

Ao utilizador é apenas permitido o descarregamento para uso pessoal, pelo que o emprego do(s) título(s) descarregado(s) para outro fim, designadamente comercial, carece de autorização do respetivo autor ou editor da obra.

Na medida em que todas as obras da UC Digitalis se encontram protegidas pelo Código do Direito de Autor e Direitos Conexos e demais legislação aplicável, toda a cópia, parcial ou total, deste documento, nos casos em que é legalmente admitida, deverá conter ou fazer-se acompanhar por este aviso.

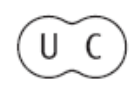



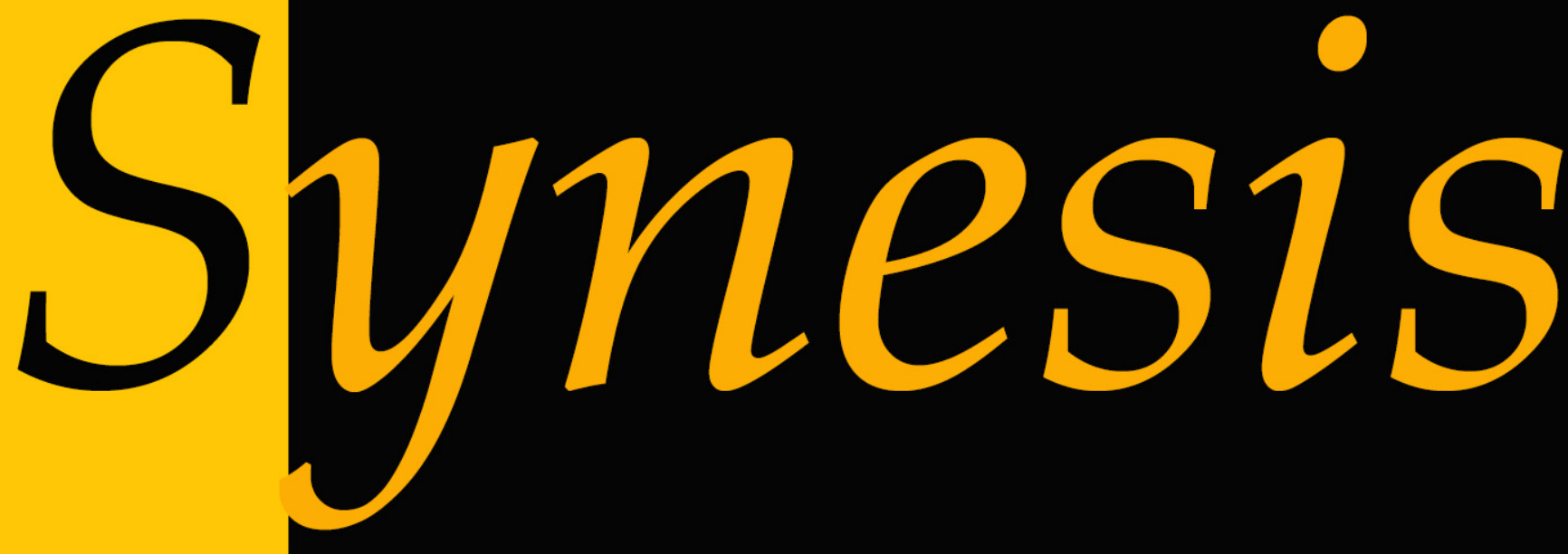

Revista do Centro de Teologia e Humanidades ISSN 1984-6754

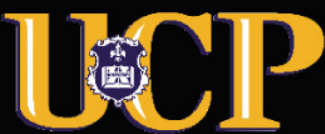




\section{HANNAH ARENDT E O "MILAGRE" DA NATALIDADE}

José João Neves Barbosa Vicente ${ }^{2}$

Resumo: Este artigo apresenta a atitude de Arendt diante do mal praticado pelos regimes totalitários. Ou seja, apesar de conviver e refletir os horrores do totalitarismo, Arendt acredita, com fundamento em seu conceito de natalidade, na possibilidade de um mundo diferente onde as instituiçóes políticas possam garantir a manifestaçáo da liberdade.

Palavras-chave: Política; liberdade; nascimento; começo; mentira.

Abstract: This article presents Arendt's attitude toward evil practiced by totalitarian regimes. That is, although her coexistence and reflection about the horrors of totalitarianism, Arendt believes, with basis in its concept of natality, the possibility of a different world where the political institutions can guarantee the manifestation of freedom.

Keywords: Politics; freedom; birth; start; lie.

\footnotetext{
${ }^{1}$ Artigo recebido em 21/04/2011 e aprovado para publicaçáo pelo Conselho Editorial em 9/06/2011.

${ }^{2}$ Mestre em Filosofia pela Universidade Federal de Goiás (UFG); aluno especial do curso de doutorado em Filosofia da Universidade Federal da Bahia (UFBA); e professor assistente de Filosofia da Universidade Federal do Recôncavo da Bahia (UFRB). Currículo Lattes: http://lattes.cnpq.br/3698270800560619. E-mail: josebvicente@bol.com.br.
} 
Os regimes totalitários desafiaram o sentido dos limites. De acordo com Orwell (1985, p.200.), seus líderes apresentavam-se como os detentores da "verdade absoluta" e exigiam um mundo de uma só vontade, a do chefe. Assim, para Arendt (1972, p.184) "O inferno totalitário só prova uma coisa: que o poder do homem é maior do que ele teria sequer ousado imaginar, que o homem pode concretizar visóes do inferno sem que o céu caia ou a terra se abra".

Mesmo depois de presenciar as açóes dos regimes totalitários que sem piedade decretaram o massacre de homens, ou seja, a morte da liberdade mediante a prática do genocídio ${ }^{3}$, Arendt náo deixou de acreditar na capacidade humana. Para ela, só o homem é capaz de oprimir e de privar o homem da sua liberdade e só ele, também, é capaz de garantir ao seu semelhante um espaço para a manifestação da sua liberdade. Uma postura que demonstra a preocupação da autora com este mundo e com os homens que nele habitam. Mundo que, para ela,

\begin{abstract}
não é idêntico à terra ou à natureza como espaço limitado para o movimento dos homens e condição geral da vida orgânica. Antes, tem a ver com o artefato humano, com o produto de mãos humanos, com os negócios realizados entre os que, juntos, habitam o mundo feito pelo homem. Conviver no mundo significa essencialmente ter um mundo de coisas interposto entre os que nele habitam em comum, como uma mesa se interpóe entre os que se assentam ao seu redor; pois, como todo intermediário, o mundo ao mesmo tempo separa e estabelece uma relação entre os homens (ARENDT, 1983, p.62).
\end{abstract}

A triste experiência que Arendt teve com o aparecimento dos regimes totalitários, em vez de contribuir para que ela desistisse de pensar, levou-a a tomar uma atitude semelhante a de Tocqueville (1977, p.540,) outrora. A saber, que "o passado já não

3 Num sentido jurídico, ratificado por uma convenção internacional, um massacre não é um genocídio. O genocídio é "a destruição metódica de um grupo étnico". Definição que na opinião de Alain Besançon, é insuficiente. Pois, segundo ele, muitos massacres entrariam nesta definição; e por outro lado, se se coloca em dúvida que os judeus sejam um "grupo étnico" -, o que significaria retomar a concepção nazista - a Shoah não se encaixaria nesta categoria! Para ele, um genocídio no sentido próprio do termo, relativamente ao simples massacre, requer o seguinte critério: é preciso que a matança tenha sido premeditada no quadro de uma ideologia que coloque como objetivo o aniquilamento de uma parte da humanidade a fim de impor a sua concepção do bem. O plano de destruiçấo deve englobar a totalidade do grupo visado, mesmo se ele não é levado até o fim por razóes de impossibilidade material ou de reviravolta política. $O$ único precedente conhecido poderia muito bem ser a Vendéia, que, segundo as ordens dadas pela Convençáo, deveria ser "destruída” em sua totalidade (Besançon, 2000, p.110-111.). 
esclarece o futuro" e que "o espírito marcha nas trevas", o que significa necessariamente, que "precisamos de uma nova ciência política, para um mundo inteiramente novo" ${ }^{4} \mathrm{Ou}$ seja, o totalitarismo demonstrou,

que a dignidade humana precisa de nova garantia, somente encontrável em novos princípios políticos e em uma nova lei na terra, cuja vigência desta vez alcance toda a humanidade, mas cujo poder deve permanecer estritamente limitado, estabelecido e controlado por entidades territoriais novamente definidas (ARENDT, 1989, p.13.).

Para isso, no entanto, é fundamental, de acordo com Arendt (apud, SONTHEIMER, 1999, p.9) acreditar "ser evidente que o homem é dotado, de uma maneira altamente maravilhosa e misteriosa, do dom de fazer milagre”. Esse poder de fazer milagres ao qual Arendt se refere, não é considerado, por exemplo, divino ou sobrenatural. E, portanto, não pode ser entendido como aquele poder que segundo os evangelhos, possuía Cristo, o "filho de Deus" de ressuscitar os mortos, curar o paralítico, dar visão ao cego, etc., como aparece relatado na Bíblia (no Novo Testamento), no Livro de Mateus, capítulo 9, por exemplo, ou algo que independe inteiramente dos homens. O termo milagre, em Arendt, remete antes para o poder que os homens possuem de interromper o automatismo do encadeamento causal. Significa sim, que os homens podem agir, tomar iniciativa, impor "um novo começo"

Para Arendt, o novo intervém na história de modo "milagroso" no sentido em que representa, estatisticamente, o infinitamente improvável, o irredutível a uma simples explicação causal. Assim, em 1953, na conclusão de um capítulo (Ideologia e terror) que acrescentou ao livro Origens do totalitarismo, inspirada nos ensinamentos de Santo Agostinho, Arendt vira o sonho totalitário de cabeça para baixo: se tudo era possível ao homem, como os líderes totalitários procuraram demonstrar ao levar o mal aos seus últimos extremos, isto é ao transformar os homens em espécies obedientes e

4 De acordo com a observação de Young-Bruehl (1982, p.324), a "nova ciência da política" de Arendt, considerou o homem como um ser ativo e olhou para as condições da ação humana, sem negligenciar o mal a que pode levar a perversão da ação como uma espécie de fabricação. Ela levou adiante essas tarefas em diversos contextos, mas com a mesma convicção: de que o impulso questionador que os antigos conheceram como a origem da filosofia deveria ser dirigido diretamente ao reino dos negócios humanos, "à vita activa". 
absolutamente sem vontade, então, diz a nossa autora, algo mais era possível, a saber, um novo começo. Um começo capaz de mudar radicalmente a ordem totalitária de governar os homens, um começo que garante fundamentalmente a manifestação da liberdade humana. Ou como nos lembra Ricoeur (1995 p.16), um começo capaz de "pensar a possibilidade de um mundo não - totalitário".

O reconhecimento da possibilidade de um "novo começo" significa essencialmente, acreditar profundamente que o homem é capaz de romper e inaugurar, de fazer o improvável e o incalculável, de criar um "mundo novo": um mundo não totalitário, um mundo comum, um mundo de liberdade.

A revoluçáo, por exemplo, cujo conteúdo é a liberdade política, liberdade de participar no governo, nos assuntos públicos, é para Arendt (1980, p.22-29), o tempo do começo ou do recomeço. Ou seja, no plano mais estritamente político é a revolução que ela confia esse papel de ruptura que quebra o processo de reificaçáo inerente à condição humana moderna e que anuncia, sempre promissoramente, renovação.

A revoluçáo é um pôr à prova a faculdade do homem de começar alguma coisa nova. Melhor ainda, essa ênfase de novidade que é a ruptura revolucionária não é uma insurreição de um contra os outros, mas uma exigência de felicidade para todos: o espírito revolucionário dos últimos séculos, isto é, o impulso da libertação e da construção de uma causa nova onde a liberdade se possa estabelecer, é sem precedentes e sem equivalentes em toda a história até então. Ela permite ao pensamento, por definição solitário, juntar-se ao domínio público e sua ação.

A possibilidade de um novo começo é reconhecer que o homem, conforme nos lembra Castoriadis (1985, p.9.), não só é capaz de criar "o monstruoso", mas também, de criar o "sublime". É reconhecer no fundo, que "só o homem pode proteger o homem da perda da sua humanidade, só o homem pode privar o homem dessa humanidade" (ROVIELLO, 1990, p.179.).

Essa possibilidade humana de "um novo começo" pode ser abafada, desvirtuada, ressignificada, como aconteceu nos regimes totalitários, mas jamais suprimida. Ela faz parte da condição humana, é uma das condiçóes nas quais a vida foi entregue ao homem 
para que ele dê conta da vida através desta condição. E enquanto condição humana, ela permanece como possibilidade humana em aberto para o homem, sempre, em qualquer lugar e tempo.

A "instrumentalização" da ação e a degradação da política como meio de atingir outra coisa jamais chegaram a suprimir a ação, a evitar que ela continuasse a ser uma das mais decisivas experiências humanas, nem a destruir por completo a esfera dos negócios humanos (ARENDT, 1983, p.242.).

Dentro da perspectiva arendtiana, portanto, essa capacidade humana implica necessariamente, numa recusa deliberada da categoria da causalidade e também de todos os modelos monológicos de conceber o tempo e fundamentalmente o âmbito dos negócios humanos. Conceito que, por muito tempo, tem andado de mãos dadas com a perspectiva dominadora.

Para invalidar a atividade e a participação contingente dos indivíduos, a tradição contemplativa usou e abusou dessa categoria. A recusa arendtiana da causalidade dá-se, assim, em contraposiçáo à ideia de um único começo e em respeito aos vários inícios. Para Arendt, o que concebemos hoje como realidade, o mundo terrestre, orgânico e humano, surgiu de probabilidades infinitas, ou seja, são verdadeiros milagres e, apesar disso, são dotados de máxima realidade possível. Isso quer dizer que o que chamamos real na vida ordinária veio a existir mediante coincidências. Assim sendo, as ações nas suas contingências realizam a constituição do mundo e da história humana.

O ser humano não será definitivamente controlado pela lógica e previsibilidade totalitária. Os governos totalitários encontram seus limites na própria condição dos homens: a capacidade que eles têm de serem livres e criarem novas realidades, e que não pode ser refreada nem mesmo pelo mais feroz sistema de domínio. Criar novas realidades, não significa para Arendt, partir sempre de algo absolutamente novo. Pois, 
Por ser "criado para que houvesse um começo" (ARENDT, 1989, p.531.), ou seja, capaz de agir, significa de acordo com Arendt (1983, p.191), "que se pode esperar dele o inesperado, que ele é capaz de realizar o infinitamente improvável". Contrariar e romper totalmente com a lógica totalitária de deduzir rigorosamente uma conclusáo das premissas.

Esse "novo começo", esse milagre de que o homem é capaz, "só é possível porque cada homem é singular, de sorte que, a cada nascimento, vem ao mundo algo singularmente novo" (ARENDT, 1983, p.191). Deste modo, a fonte suprema que garante ao homem esse "poder de fazer milagres", ou seja, esse poder "de sempre iniciar algo novo" (ARENDT, 1973, p.15), capaz de salvar o mundo está no fato da natalidade: o mais notável de todos os acontecimentos. Pois, traz ao mundo, imprevisíveis possibilidades guardadas dentro de uma única e insubstituível pessoa no início de sua vida.

Essa esperança e essa fé no mundo encontram sem dúvida sua expressão mais sucinta, porém mais gloriosa, de acordo com Arendt, no anúncio dos evangelhos da Bíblia: nasceu-nos um menino:

O milagre que salva o mundo, a esfera dos negócios humanos, de sua ruína normal e "natural" é, em última análise, o fato do nascimento, no qual a faculdade de agir se radica ontologicamente. Em outras palavras, é o nascimento de novos seres humanos e o novo começo, a ação de que são capazes em virtude de terem nascido. Só o pleno exercício dessa capacidade pode conferir aos negócios humanos fé e esperança, as duas características essenciais da existência humana que a antiguidade ignorou por completo, desconsiderando a fé como virtude muito incomum e pouco importante, e considerando a esperança como um dos males da ilusão contidos na caixa de Pandora (ARENDT, 1983, 259).

O domínio total, projeto dos regimes totalitários que, através da ideologia e do terror pretendiam implantar e organizar um espaço para que os homens se tornassem absolutamente desprovidos de mundo em seu caráter "comum" e "humano" para que fosse possível dispensar a opiniáo ou qualquer auxilio humano para a instituição e a preservaçáo do mundo, qualquer traço de espontaneidade e imprevisibilidade, não 
permanecerá para sempre. No "novo começo" temos a oportunidade, ou melhor, a capacidade de agirmos como se tivéssemos de fundar nossa existência de novo.

Se o totalitarismo nega o princípio básico de qualquer política: o princípio da medida, podemos pensar o seu contrário absoluto. Isto é, pensar o político como "paciência e mediaçâo" (ABENSOUR, apud ROVIELLO, 1990, p.29.), onde a lei, a ação concentrada e o debate surgem, de acordo com Arendt, como as três figuras fundamentais da mediação política, capazes de criar um espaço entre os indivíduos, que, ao mesmo tempo, os separa e os une. Pensar uma política baseada no fato da pluralidade dos homens, levando em consideração que ela deve, portanto, organizar e regular o convívio de diferentes, não de iguais. A pluralidade apresenta-se fundamentalmente como a medida e o limite da ação política, em dois sentidos essenciais: sem a presença e a companhia dos outros não existe ação; uma ação na qual o outro é destruído não é mais política.

A partir do momento que se destrói a alteridade está-se negando a "estrangeiridade essencial" reinante entre os homens, isto é, o fato de cada um ser singular e único. As vidas singulares perdem sua dignidade quando se destrói o contexto plural da esfera pública e facilmente podem ser ceifadas da terra. A essência do sentido político da Açáo em Arendt reside fundamentalmente na noção de pluralidade. Ela quer, através desse conceito, afirmar que a dignidade humana não pode ser subsumida num valor absoluto ou externo, mas no reconhecimento das vozes e poder dos cidadáos nos seus destinos.

Haverá talvez verdades que ficam além da linguagem e que podem ser de grande relevância para o homem no singular, isto é, para o homem que, seja o que for, não é um ser político. Mas, os homens no plural, isto é, os homens que vivem e se movem neste mundo, só podem experimentar o significado das coisas por poderem falar e ser inteligíveis entre si e consigo mesmos (ARENDT, 1983, p.12).

Tudo o que os homens fazem, sabem ou experimentam só tem sentido, de acordo com Arendt, na medida em que pode ser discutido. Pois, é em razão das 
diferenças que surgem as relaçóes políticas, as promessas e os pactos originadores da esfera pública.

A garantia da realidade na pluralidade vem do outro, jamais de uma esfera externa às relações humanas, pois, conforme nos lembra Hannah Arendt, viver num mundo real e discuti-lo com os outros é no fundo a mesma coisa (ARENDT, 1983, p.189.).

A pluralidade, da perspectiva de Arendt, não necessita de representante; por isso mesmo, é que toda a ação implica, sempre, na presença dos outros, realizada sempre em comum. O iniciador náo manda, age com e em concerto. A pluralidade é a garantia fundamental contra toda e qualquer desmesura: dominaçáo, tirania etc.

A humanidade sem a possibilidade de agir e falar não passa de ficção. Pois, conforme nos lembra Arendt, a ação e o discurso são os meios pelos quais os seres humanos se manifestam uns aos outros, não como meros objetos físicos, mas enquanto homens.

Portanto, a ideia de pluralidade diz respeito, segundo a nossa autora, a intermediação da fala e da ação substituindo assim, os instrumentos e a força, na disputa pelo reconhecimento. Assim, a grandeza da política reside essencialmente nessa possibilidade de destaque dos indivíduos sem ser ao preço da vida e dominação dos outros.

A ação e o discurso instauram um mundo onde não há um resultado tangível, mas um espaço, uma rede de relaçóes testemunhada e confirmada por todos que a ela acedem. Se a ação fosse previsível, certamente ela deixaria de revelar o agente e na verdade, o que iria aparecer seria o objeto com sua conformaçáo a uma imagem previamente estabelecida, isto é, estaríamos no campo da fabricação.

Como a açáo não parte de uma imagem a ser realizada, o que na sua realizaçáo aparece são as palavras e os feitos de um agente, o próprio agente revelando-se sem que se conheça a si mesmo ou saiba de antemáo "quem" revela. Desse modo, a incerteza é um aspecto básico de todo intercambio direto entre os homens, sem a mediação solidificadora e estabilizadora das coisas (AGUIAR, 2001, p.91). 
Em toda ação, diz Arendt, o que é verdadeiro e essencial em primeiro lugar para aquele que age é a revelação da sua própria imagem; ou seja, de acordo com a nossa autora, ninguém age se, agindo, não torna manifesto seu si mesmo oculto. "Esta revelação de quem alguém é está implícita tanto em suas palavras quanto em seus atos” (ARENDT, 1983, p.191).

Sendo assim, nos lembra Arendt (1983, p.248-249), a incerteza é um dos aspectos fundamentais de todo intercâmbio direto entre os homens. É, portanto, em função dessa indeterminação que os homens constituem o seu poder: fazem promessas, realizam pactos e fundam Estados. O sentido dessas promessas e pactos está fundamentalmente em oferecer aos indivíduos um espaço para revelação da individualidade

Para remediar as características básicas da ação humana - imprevisibilidade e irreversibilidade, Arendt aposta nas capacidades humana de "prometer", que estabiliza o futuro e remedia a imprevisibilidade da ação; e de "perdoar", que redime os feitos humanos no passado. Duas virtudes de origens judaicas-cristão dos quais a autora abstrai o aspecto mais propriamente religioso para desvendar-lhes a forte dimensão política.

As duas faculdades são aparentadas, pois a primeira delas - perdoar - serve para desfazer os atos do passado, cujos "pecados" pendem como espada de Dâmocles sobre cada nova geração; a segunda - obrigar-se através de promessas - serve para criar, no futuro, que é por definição um oceano de incertezas, certas ilhas de segurança, sem as quais não haveria continuidade, e menos ainda durabilidade de qualquer espécie, nas relaçóes entre os homens (ARENDT, 1983, p.249).

Portanto, se as consequências involuntárias das ações dos homens não podem ser de maneira alguma desfeitas, ao menos eles podem perdoar uns aos outros e, deste modo, restabelecer a possibilidade de um novo começo. Se os homens jamais podem ter certeza quanto aos resultados futuros de suas açóes, ao menos eles podem comprometerse mutuamente, estabelecendo "ilhas de segurança" sem as quais nem mesmo a continuidade, para não falar da durabilidade de qualquer coisa, jamais seria possível nas 
relaçóes entre os homens.

Colocar em prática a possibilidade de um "novo começo", é no fundo, reabilitar o mundo das opinióes, a doxa que Platáo dispensara em troca do ideal absoluto e universal como fundamento último para as questôes dos assuntos humanos. É evidenciar a qualidade comum deste mundo, segundo a infinita diversidade dos pontos de vista dos homens, onde impera o discurso capaz de expressar e preservar nossa civilidade.

A vida sem discurso e sem ação definitivamente, para a nossa autora, não tem sentido algum, ela deixa de ser uma vida humana, uma vez que já não é vivida entre os homens. "É com palavras e atos que nos inserimos no mundo humano; e esta inserção é como um segundo nascimento, no qual confirmamos e assumimos o fato original e singular do nosso aparecimento físico original" (ARENDT, 1983, p.189).

"A civilização, refletida na linguagem, é o jardim onde crescem as relações; fora dele, está o abismo selvagem" (NEMEROV, apud KARIEL, 1966, p.82.). Esse maravilhoso sentido do novo foi, certamente, a motivação essencial que levou Arendt a escrever. É uma característica que permanecerá enquanto permanecer o mundo. Afinal, "o curso do mundo", só poderá "ser determinado e previsto, de maneira determinística”, quando em todos os cantos do planeta, todos "os recém-nascidos" forem absolutamente "privados de sua espontaneidade e de seu direito a começar algo novo" (ARENDT, 1999, p.58.).

\section{Consideraçóes finais}

Este artigo apresentou uma abordagem interpretativa da atitude de Arendt diante do mal praticado pelos regimes totalitários, a partir de uma análise do seu conceito de "natalidade". A reflexão sobre o projeto totalitário de desmundanização do mundo e desumanização dos homens permitiu à Arendt considerar o "fato da natalidade" como possibilidade de um "novo começo", capaz de instaurar e preservar o mundo humano e comum. Isto é, um mundo enquanto abrigo e assunto dos homens. O "milagre" da natalidade reflete a atitude de Arendt em analisar o homem enquanto autor do artifício 
humano e como um ser envolvido com os outros homens por meio da ação e da fala.

\section{Referências Bibliográficas}

AGUIAR, Odílio. Filosofia e politica no pensamento de Hannah Arendt. Fortaleza: EUFC, 2001 .

ARENDT, Hannah. A condição humana. Rio de Janeiro: Forense, 1983. . Le système totalitaire. Paris: Seuil, 1972 . Crises da república. Sáo Paulo: Perspectiva, 1973. - Da revolução. Tradução de Fernando Dídimo Vieira. São Paulo: Ática-UnB, 1980. . Da violência. Brasília: UnB, 1985. . Eichmann em Jerusalém. Tradução de Sonia Orieta Heinrich. São

Paulo: Diagrama e Texto, 1983. . O que é politica? Tradução de Reinaldo Guarany. Rio de Janeiro:

Bertrand Brasil, 1999.

. Origens do totalitarismo. Tradução de Roberto Raposo. São Paulo:

Companhia das Letras, 1989.

BESANÇON Alain. A infelicidade do século: sobre o comunismo, o nazismo e a unidade da shoah. Rio de Janeiro: Bertrand Brasil, 2000.

CASTORIADIS, Cornelius. Os destinos do totalitarismo e outros escritos. Porto Alegre: L e PM, 1985.

KARIEL, Henry. Aspectos do pensamento politico moderno. Rio de Janeiro: Zahar, 1966.

RICOEUR, Paul. Leitura 1: em torno ao político. São Paulo: Loyola, 1995.

ROVIELlO, Anne-Marie. Senso comum e modernidade em Hannah Arendt. Lisboa: Piaget, 1990.

SONTHEIMER, Kurt. Prefácio. In: ARENDT, Hannah. O que é política? Fragmentos das obras póstumas compilados por Ursula Ludz. Tradução de Reinaldo 
Guarany. Rio de Janeiro: Bertrand Brasil, 1999.

TOCQUEVILlE, Alex. A democracia na América. São Paulo: Editora da Universidade de São Paulo, 1977.

YOUNG-BRUEHL, Elizabeth. Hannah Arendt: for love of the world. New York: Yale University Press, 1982. 